\title{
Production of Allyl Phenyl Carbinol (APC) by Biotrans- formation using Rhizopus arrhizus
}

\author{
Vilas B. Shukla and Pushpa R. Kulkarni* \\ Food \& Fermentation Technology Division, Department of Chemical Technology, University of Mumbai, (UDCT), \\ Matunga, Mumbai -400 019, India
}

\begin{abstract}
The objective of the present work was to study the stereoselective synthesis of homo-allylic alcohol using stereoselective hydrolysis by Rhizopus arrhizus and also to study the stereoselective synthesis of allyl phenyl carbinol (APC) or 1-Phenyl-3-butene-1-o by combination of chemical synthesis and biotransformation from cheap raw materials such as benzaldehyde and allyl bromide. Stereospecific synthesis of allyl phenyl carbinol (APC) was achieved by acetate hydrolysis by $R$. arrhizus giving $R(+)$ enantiomer. Maximum enantiomeric excess of APC was obtained at $16 \mathrm{~h}$ where as maximum yield of it was obtained at $48 \mathrm{~h}$ of biotransformation.
\end{abstract}

Key words: Allyl Phenyl Carbinol, Biotransformation, Rhizopus arrhizus

\section{INTRODUCTION}

Asymmetric hydrolysis of recemic esters or esterification of recemic alcohols are the main routes for the synthesis of chiral carbinols. Use of $\mathrm{R}$ enantiomer of allyl phenyl carbinol (APC) or 1Phenyl-3-butene-1-ol for preparation of valuable intermediates for drugs and agro-chemicals (Hosomi 1988), and for preparation of substituted cyclophosphamide analogues for treatment of leukaemia of the cells resistant to cyclophosphamide (Borch and Canute 1989, 1991) is well reported. Chemical synthesis of $\mathrm{R}$ enantiomer of APC is desribed by Keck et al. (1993) and Mathre et al. (1993). Synthesis of S enantiomer has also been reported (Barrett et al. (1986), Hoffman \& Herold (1991)).However biotransformation is known to offer several advantages over the traditional chemical synthesis like reaction specificity, regiospecificity, stereospecificity and requirements of mild conditions. Enantioselective hydrolysis of recemic acetate of APC by crude pig liver acetone powder has been successful in giving 56-72\% optical purity (Basavarajah et al. 1990). The mould Rhizopus arrhizus has proved its versatility for reduction of a variety of carbonyl compounds and hydrolysis of acetates (Patil et al. 1993, 1996, Salvi et al. 1995a, b). However, stereospecific synthesis of APC using microbial biotransformation has not been reported so far. Therefore preliminary attempts were made to use the acetate hydrolysis activity of Rhizopus arrhizus for yielding stereospecific APC with a view to avoiding harsh experimental conditions and use of costly raw materials. For this, first chemical synthesis of the substrate was achieved and then it was subjected to biotransformation.

\section{MATERIALS AND METHODS}

Micro-organism Rhizopus arrhizus (NCIM 997) was obtained from National Collection of Industrial Micro-organisms, National Chemical Laboratory, Pune. The culture was maintained on PDA (Hi-Media) slants.

Chemical synthesis of $( \pm)$ 1-phenyl-3-butene-1ol : This was synthesised from benzaldehyde, allyl bromide, using activated zinc by Christian and Luche's method (1985). The purified compound was confirmed on the basis of FT-IR spectrum of the compound.

Chemical synthesis of $( \pm)$ 4-acetoxy-4-phenyl-1butene (A) : This was obtained by acetylation (Furniss et al. 1989) of ( \pm ) 1-phenyl-3-butene-1-ol and confirmed on the basis of FT-IR.

\footnotetext{
"Author for correspondence
} 
Biotransformation studies : $10^{6}$ spores of fungus $R$. arrhizus were inoculated into $150 \mathrm{ml}(500 \mathrm{ml}$ conical flask) of sterilised modified Czepek Dox medium (M/s. Hi-Media Ltd. Mumbai) (Prema and Bhattacharya 1962). The organism was allowed to grow on a rotary shaker at $180 \mathrm{rpm}$ and $30 \pm 2^{\circ} \mathrm{C}$ for $72 \mathrm{~h}$. The substrate viz. $( \pm) 4$-acetoxy 4-phenyl -1-butene (A) (100 mg) was dissolved in $1 \mathrm{ml}$ of $95 \%$ ethanol and added into flasks containing grown $R$. arrhizus. The reaction was allowed to take place on a rotary shaker for different periods. A substrate control (with substrate but without micro-organism) and organism control (with organism but without substrate) were also run simultaneously. The complete scheme is shown in the Fig.1.

Analysis of products : At the end of biotransformation, the mycelial mass was filtered from the culture medium. The filtrate was extracted with chloroform (M/s. S. D. Fine Chemicals Ltd. Mumbai) ( 3 x 100ml) washed with water $(2 \times 20 \mathrm{ml})$ and dried over anhydrous $\mathrm{Na}_{2} \mathrm{SO}_{4}$. The solvent was removed under reduced pressure and the residue obtained was monitored on TLC (Silica gel- G, M/s. Merck India, Mumbai) using hexane : diethyl ether : glacial acetic acid $(80: 20: 2 \mathrm{v} / \mathrm{v})$ as a solvent system. The control flasks were also extracted similarly. The product were purified by preparative TLC. using 5\% ethyl acetate in pet ether (60-80). The compounds purified as above were tested for purity using GC and NMR as well as subjected to Chiral HPLC as follows. ${ }^{1} \mathrm{H}$ NMR Spectra were recorded on Varian EM-360 $60 \mathrm{MHz}$ using $\mathrm{CDCl}_{3}$ solvent and chemical shifts were given in parts per millions from Tetramethyl silane as internal standard. IR Spectra were recorded on Perkin-Elmer IR Spectrophotometer model 783. GC analysis was carried out on a Shimadzu Gas Chromatograph GC-16A with FID detector. A column 3\% OV-17 (80-100 mesh) was used with nitrogen flow at $40 \mathrm{ml} / \mathrm{min}$. Initial temperature was $90^{\circ} \mathrm{C}$ and final temperature was $240^{\circ} \mathrm{C}$, rate of heating used was $4^{\circ} \mathrm{C} / \mathrm{min}$. Retention time of 1-phenyl-3-butene-1- ol, was $9.17 \mathrm{~min}$. The chiral analysis of purified 1phenyl 3-butene obtained was done on Jasco - PU 980 HPLC with UV 975 as detector $(220 \mathrm{~nm})$. Column used was Chirex - 3001 (ss) having dimension $4.67 \times 25 \mathrm{~cm}$. Mobile phase used was $0.2 \%$ isopropyl alcohol and $2 \%$ dichloro ethylene in $\mathrm{n}-$ Hexane. Flow rate of the solvent system was $1.0 \mathrm{ml} / \mathrm{min}$. Amount of sample injected used was $20 \mu \mathrm{l}$.

\section{RESULTS AND DISCUSSION}

Initially substrate used for biotransformation was chemically synthesised and confirmed on the basis of the FT-IR spectrum of substrate. As the previous reports on biotransformation of different substrates by acetate hydrolysis activity by the same organism have suggested at least $48 \mathrm{hrs}$ for more enantioselective synthesis of products (Patil et al. 1993, 1996, Salvi et al 1995 ${ }^{\mathrm{b}}$ ) in this biotransformation the level of products was determined at various time intervals after $16 \mathrm{~h}$. The extracts from supernatant were subjected to TLC. The extract showed presence of both 1-phenyl-3butene-1-ol and unreacted substrate. Purification of extract gave product obtained by acetate hydrolysis reaction. The yields and enantiomeric excess of the product and yield and specific optical ratation of unreacted substrate are as shown in the Table 1. The maximum yield of $\mathrm{R}(+)$ was observed at $16 \mathrm{~h}$ of biotransformation whereas the maximum yield was at $48 \mathrm{~h}$ of biotransformation. Beyond $48 \mathrm{hs}$ both the yield and enantiomeric excess decreased. This is the first report on biotransformation of ( \pm ) 4-acetoxy-4-phenyl-1butene synthesised from benzaldehyde and allyl bromide to $\mathrm{R}(+)$ 1-phenyl-3-butene-1-ol using Rhizopus arrhizus. The ${ }^{1} \mathrm{H}$ NMR of the product so obtained gave peaks at frequency $(\delta \mathrm{ppm})-7.3$ $7.7 \mathrm{~m}$ (-Ar), 5.7 - $6.3 \mathrm{~m} \mathrm{(-CH),} 5.3-5.5 \mathrm{~s}(-\mathrm{CH} 2)$, 4.7- $4.9 \mathrm{~s}(-\mathrm{CH}-\mathrm{OH}), 2.2-2.5 \mathrm{t}(=\mathrm{CH} 2), 2.6-2.7 \mathrm{~s}$ $(-\mathrm{OH})$ confirming identity of 1-phenyl-3-butene-1ol. 
C H E M IC A L S Y N T H E S IS
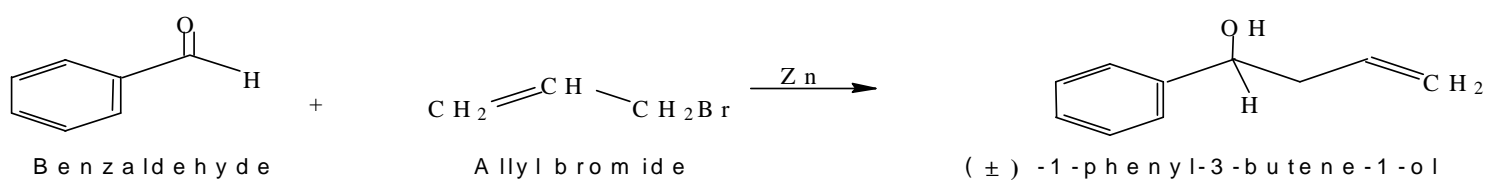

( \pm ) $-1-$ phen y l-3-buten e - $1-$ ol

i) A cetic anhydride

ii) $P$ y rid in $e$

( A c e tylation)

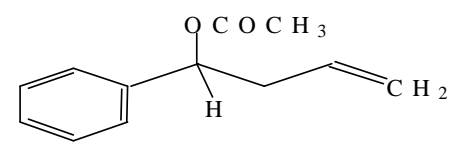

( \pm ) - 4 -phenyl-4-acetoxy butene (A)

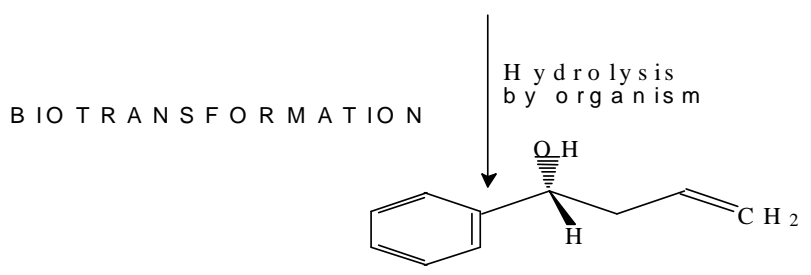

R (+) - 1-phen y I-3-buten e-1-ol

Figure 1 - Scheme for chemical synthesis and biotransformation of 4-phenyl-4-acetoxy butene

Table 1 - The enantiomeric excess and yield of 1-phenyl-3-butene-1-ol obtained by acetate hydrolysis and specific optical rotation and yield of unreacted substrate of biotransformation

\begin{tabular}{|c|c|c|}
\hline $\begin{array}{l}\text { Time of } \\
\text { biotransformation }\end{array}$ & 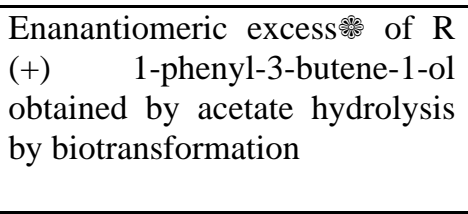 & $\begin{array}{l}\text { Specific optical rotation }[\alpha]_{\mathbf{D}}^{27} \text { in Benzene } \\
\text { (0.6 c) and yield of unreacted substrate (4-acetoxy- } \\
\text { 4-phenyl-1-butene) }\end{array}$ \\
\hline $16 \mathrm{hrs}$ & $71.13(47.2)$ & $-57.61(15.5)$ \\
\hline $24 \mathrm{hrs}$ & $67.27(47.9)$ & $-64.06(13.1)$ \\
\hline $48 \mathrm{hrs}$ & $56.13(49.1)$ & $-65.24(8.6)$ \\
\hline $72 \mathrm{hrs}$ & $54.63(43.4)$ & $-65.52(7.6)$ \\
\hline
\end{tabular}

- Obtained by Chiral HPLC analysis. Figures in the paranthesis indicate yield/100 $\mathrm{mg}$ of substrate

\section{REFERENCES}

Barrett A. Beali G.M. Gibson J.C. and Vernom C. (1986) Tendem asymmetric alkylboration alkene metathesis : A novel stratergy for the synthesis of trans - disubstituted homoallylic alcohols Chemical. Commun. 19, 2229-2230.

Basavarajah D. Rao P. and Dharma D. (1990) Enantioselective hydrolysis of recemic acetates of homoallyl alcohol by Crude Pig Liver Acetone Powder (PLAP) Synth. Commun. 20(19), 2945-2947.
Borch R.F. and Canute G.W.(1989) Cyclophosphamide analogs useful as antitumer agents PCT Int. Ap. W0 8911, 257 (CA-113:126596u).

Borch R.F. and Canute G.W. (1991) Synthesis and antitumer properties of activated cyclophospha-mide analogs J. Med. Chem. 34(10), 3044-52.

Christian P. and Luche J. (1985) Allylzinc reagent addition in aquous media J. Org. Chem. 50, 910-912.

Furniss B.R. Hannaford A.J. Smith P.W.G. and Thatchell A.R. (1989) Vogel's Text book of Practical Organic Chemistry $5^{\text {th }}$ edition Longman Scientific and Technical UK p. 698. 
Hoffman R.W. and Herold T. (1991) Stereoselective synthesis of alcohols VII : Optically active homoally alcohol via addition of chiral boronates to aldehydes Chem. Ber. 114(1), 375-383 (CA- 94:191601v).

Hosomi A.(1988) (Mitsubishi Kasai Corp.) Preparation of homoallylic alcohols as intermediates for drugs and agrochemicals Jpn Kokai Tokyo Koho Jp 63, 528,488 (CA-110:21225j).

Keck G.E. Tarbet K.H. and Geraci L.S.(1993) Catalytic asymmetric allylation of aldehydes J. Am. Che. Soc.115(18), 8467-8468.

Mathre D.J. Thomson A.S. Douglous A.W. Hoogsten K. and Corroll J. D. (1993) A practical process for preparation of tetrahydro - 1 - methyl - 3, 3 diphenyl $3 \mathrm{H}, 3 \mathrm{H}$ pyrrollo $(1,2 \mathrm{C})[1,3,2]$ oxacarborole borone : A highly enantioselective stoichiometric and catalytic reducing agent J. Org. Chem. 58 (10) 2880-2888

Patil P.N. Chattopadhyay A. Udupa S. R. and Banerji A.(1993) Biotransformation with Rhizopus arrhizus : Preparation of enantiomers of sucatol Biotechnol. Lett. 15(4), 367-372.
Patil P.N. Salvi N.A. Udupa S.R. and Banerji A. (1996) Enantiomeric synthesis of pyridyl - 1 - ethanol using Rhizopus arrhizus Biotechnol. Lett. 18(2), 159-162.

Prema B.R. and Bhattacharya P.K. (1962) Microbial transformation of terpenes II. Transformation of $\alpha$ pinene Appl. Microbiol.10, 524-528.

Salvi N.A. Patil P.N. Udupa S.R. and Banerji A.(1995a) Biotransformation with Rhizopus arrhizus :Preparation of the enantiomer of 1 - phenylethanol and 1 - (o-, m- and p- methoxy-phenyl ethanol Tet. Asymmetry 6(9), 2287- 2290.

Salvi N.A. Rane S. S. and Udupa S.R. (1995b) Microbial synthesis of $S(+)$ - 1 - (2-furyl) - 3 pentanol : A pheromone intermediate of Bark beetle Biotechnol. Lett. 17(3), 285-290.

Received: October 10, 1999; Revised: January 28, 2000; Accepted March 21, 2000. 